REGESCONCELOS \& JERÔNIMO, v(8), no 8, p. 1794-1804, SET-DEZ, 2012.
Rev. Elet. em Gestão, Educação e Tecnologia Ambiental (e-ISSN: 2236-1170)

\title{
HIDROPONIA COMO ALTERNATIVA DE USO E OCUPAÇÃO DO SOLO EM ÁREAS DEGRADADAS POR PARQUES EÓLICOS: AVALIAÇÃO DE IMPACTOS AO MEIO AMBIENTE
}

\author{
Rykson R. R. de Vasconcelos ${ }^{1}$, Carlos E. de M. Jerônimo ${ }^{2}$ \\ ${ }^{1}$ Biologo. Especialização em Perícia e Gestão Ambiental (UNI-RN). \\ ${ }^{2}$ Doutor em Engenharia Química.
}

http://dx.doi.org/10.5902/223611707164

\section{RESUMO}

Há centenas de anos o Brasil vem passando por um processo de desenvolvimento, onde desde a época de seu descobrimento a extração e uso de seus recursos naturais vem sendo feito de maneira descontrolada, degradando vastas áreas, bem como os solos que habitamos e dependemos para nosso suprimento alimentar. Especialmente a atividade da agricultura desponta como uma grande responsável nesse cenário, porém, acompanhada de perto de inúmeras atividades exploratórias. Diante desta problemática, a ciência vem estudando maneiras de recuperar ou reutilizar áreas que passam ou passaram por processos de degradação física, química ou biológica. Neste trabalho, é feita uma proposta de uso de técnicas de cultivo hidropônico com alface e milho, como forma alternativa de uso do solo, bem como o uso racional de água, dando condições de desenvolvimento da agropecuária nestas áreas. É feita uma avaliação, sobretudo, como uma avaliação de uso desse modelo como uma alternativa de compensação ambiental e reuso de esgotos ou efluentes oriundos de atividades da exploração do petróleo, montagem de usinas eólicas ou mesmo atividade de mineração.

Palavras-chave: Hidroponia, Áreas Degradadas, Meio Ambiente.

\section{ABSTRACT \\ HYDROPONICS ALTERNATIVE USE AND OCCUPATION OF LAND IN DEGRADED AREAS: CROP CORN AND LETTUCE}

There are hundreds of years Brazil has been undergoing a process of development, where from the time of its discovery the extraction and use of natural resources is being done in an uncontrolled way, degrading vast areas and the soil we inhabit and depend for our food supply. Especially the activity of agriculture emerges as a great responsibility in this scenario, however, closely followed numerous exploratory activities. Faced with this problem, science has been studying ways to recover or reuse areas that are or have undergone degradation processes physical, chemical or biological. In this paper, a proposal is made to use hydroponic techniques with lettuce and corn, as an alternative form of land use, as well as the rational use of water, providing conditions for the development of agriculture in these areas. An evaluation mainly as a review of the use of this model as an alternative environmental compensation and reuse of sewage or effluent from activities of oil exploration, installation of wind farms or mining activity.

Keywords: Hydroponics, Degraded Areas, Environment. 


\section{INTRODUÇÃO}

Há muitos anos podemos observar o avanço na ação de degradação pelo ser humano ao meio ambiente. Este processo se agrava a cada ano, com o desenvolvimento tecnológico, com a criação de máquinas maiores e mais potentes, juntamente com o aumento populacional e a necessidade de consumo da população humana, que mesmo com o grande apelo às causas ambientais, vem sendo levantadas nos dias de hoje.

A necessidade do desenvolvimento industrial e econômico é de extrema importância para todo mundo, mas dentro desta necessidade temos a criação de uma grande problemática, ou seja, aliar o desenvolvimento industrial e econômico a o uso sustentável do meio ambiente e de seus recursos. Este extrativismo desenfreado dos recursos ambientais, bem como o uso descontrolado e desordenado do solo, faz com que nosso meio ambiente seja destruído rapidamente como podemos observar nos dias atuais, pois vivemos em uma sociedade de consumo e sem o conhecimento e educação ambiental para desenvolver este tão indispensável, desenvolvimento sustentável. "O agente causador de degradação ambiental e sempre o ser humano: processos naturais não degradam, apenas causam mudanças" (Johnson et al., 1997).

O extrativismo de madeira, devastação das florestas, principalmente de biomas como a caatinga (que já sofre com as secas e suas dificuldades nutricionais por está em um ambiente árido) e em alguns casos hostil vêm gerando uma devastadora destruição destes ambientes, conforme exemplo demonstrado na Figura 1). Propiciando a inutilização destas áreas para os mais diversos fins de agricultura. Segundo Sanchez (2008), degradação ambiental seria, assim, uma perda ou deterioração da qualidade ambiental.

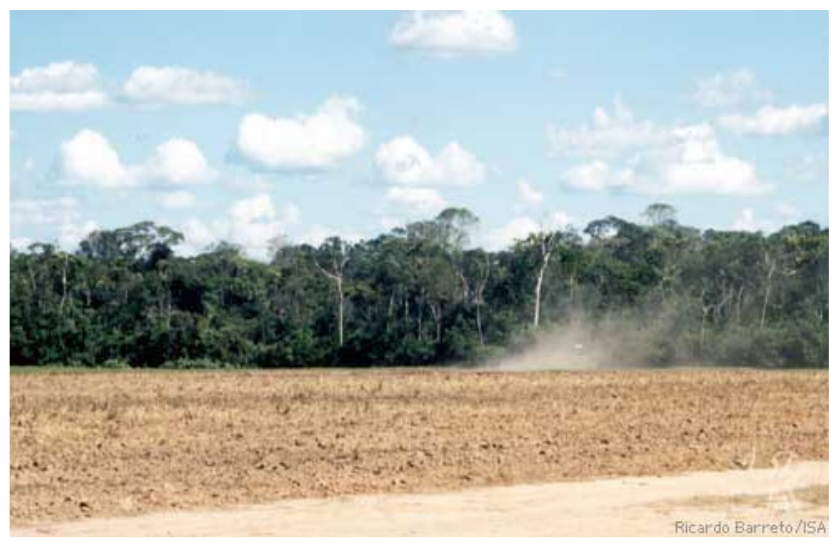

Figura 1: Área de extração de madeira, provocando a perca da camada fértil do solo. Fonte: Instituto Sócio Ambiental (2007).

Um dos fatores mais ocorrentes, principalmente na região nordeste do Brasil é a Desertificação, ação natural ou induzida que gera a determinados ambientes a perca de sua camada orgânica, inviabilizando a utilização do solo para quaisquer fins de plantio. Esta situação vem se agravando a cada ano no país e deixando mais séria a situação da agropecuária, por exemplo, a Figura 2. 


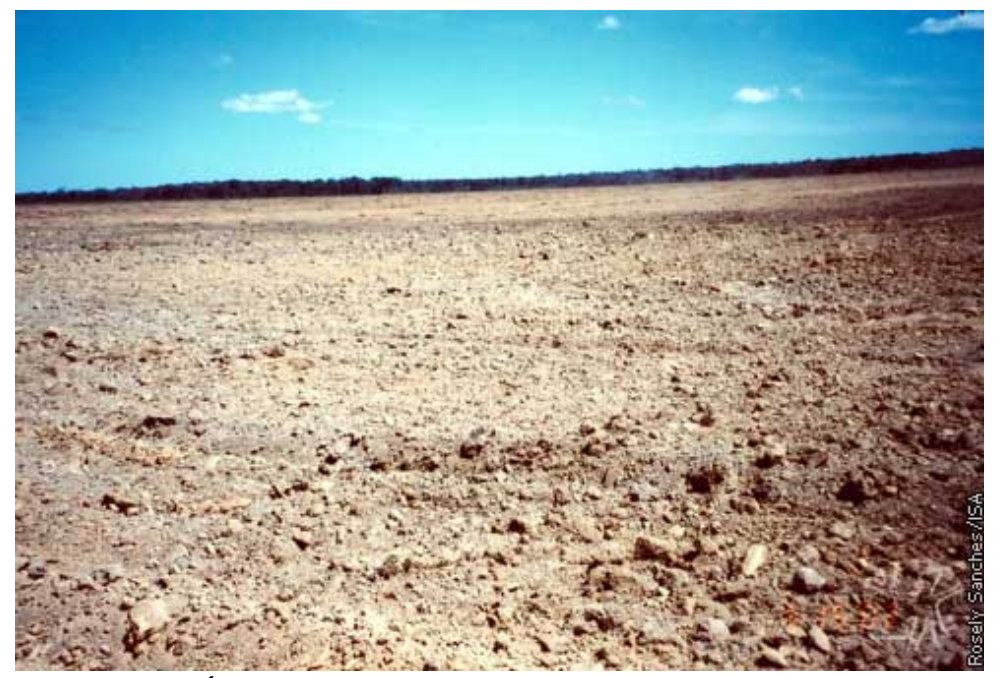

Figura 2: Área degradada em processo de desertificação.

Fonte: Instituto Sócio Ambiental (2007).

Como uma forma de frear esse desenvolvimento com fontes consideradas "sujas", ressurgimento das energias renováveis dá-se a partir dos choques petrolíferos da década de 70. Por um lado, a necessidade de assegurar a diversidade e segurança no fornecimento de energia e, por outro lado, a obrigação de proteger o ambiente, cuja degradação é acentuada pelo uso de combustíveis fósseis, o que motivou o novo interesse pelas renováveis.

Segundo Castro (2009) a energia eólica é hoje em dia vista como uma das mais promissoras fontes de energia renováveis, caracterizada por uma tecnologia madura baseada principalmente na Europa e nos EUA. As turbinas eólicas, isoladas ou em pequenos grupos de quatro ou cinco, e, cada vez mais, em parques eólicos com quarenta e cinqüenta unidades, são já um elemento habitual da paisagem de muitos países europeus, nomeadamente a Alemanha, Dinamarca, Holanda e, mais recentemente, o Reino Unido e a Espanha. Nos EUA, a energia eólica desenvolveu-se principalmente na Califórnia com a instalação massiva de parques eólicos nos anos 80. A energia eólica tem registrado nos últimos anos uma evolução verdadeiramente assinalável, no nordeste brasileiro isso é observado em diferentes estados e zonas. Para ter uma idéia da taxa de crescimento verificada na potência eólica instalada a nível mundial, demonstra um crescimento anual a taxas superiores a $100.000 \mathrm{MW}$ por ano, a partir de 2008.

Embora à energia eólica estejam associados a benefícios ambientais significativos do ponto de vista da emissão de substâncias nocivas à atmosfera, existem outros aspectos ligados com a preservação do ambiente que não podem ser negligenciados. É indispensável que os projetos sejam adequadamente integrados na paisagem e desenvolvidos em colaboração com as comunidades locais, para manter o apoio da opinião pública a esta forma de energia. Além disso, a maioria desses empreendimentos tem associado um grande dano as áreas onde são implementados, sobretudo, associados aos processos de erosão, exposição severa do solo e outros danos que tornam tais áreas consideradas como degradadas. 
Há poucos anos vem sendo estudadas técnicas e medidas para conter ou dar uso para estes locais afetados pelos diversos fatores citados e uma tendo em vista a não utilização destes solos por suas possíveis e diversas inviabilidades.

Como uma forma de minimizar o uso e ocupação do solo diversos autores (Travassos et al, 2011; Santos Junior et al, 2011; Maciel et al, 2011) vem pensando em uma forma de utilizá-lo de uma maneira indireta, e para isso apontam as técnicas de hidroponia (estudada e difundida há anos em todo o mundo) como uma boa alternativa para sanar esta problemática em alguns casos.

Desde o século XVII vêm sendo desenvolvidos os experimentos de cultivo sem o uso de terra, sendo estes aperfeiçoados com o decorrer dos séculos, com o objetivo de utilizá-lo em locais não propícios para o cultivo tradicional. Até que na década de 90 essa técnica foi mais bem estudada e expandida, sendo utilizada na Segunda Guerra Mundial onde os solos ficaram parcialmente contaminados com componentes químicos e radioativos, havendo a necessidades de se obter outras formas de cultivo para a agricultura familiar e de subsistência. Desde então, são inúmeras as pesquisas voltadas a otimização do cultivo hidropônico, conforme François (1996), Rebouças (1999) e Dias et al (2010).

Com esse objetivo foi desenvolvida e expandida a hoje chamada hidroponia, que consiste em técnicas de cultivo a base exclusivamente de água, sendo nela diluído todos os macros e micronutrientes que as plantas receberiam no cultivo tradicional. Assim, apresentamos com esta técnica, o cultivo de milho e alface, em menor espaço de tempo que os convencionais, com ênfase no melhor aproveitamento e na maior preservação dos nossos recursos naturais, conforme pode ser observado nas Figuras 3 e 4, em dois estilos de produção diferenciados.

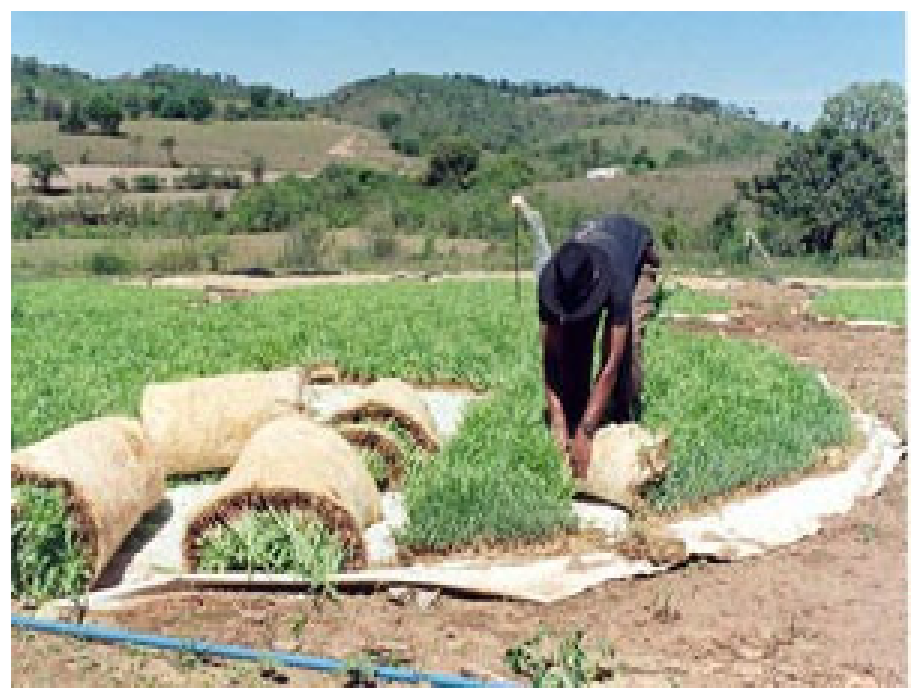

Figura 3: Cultivo hidropônico de milho para uso como forragem. Fonte: Centro de Produção Técnica - CPT (2011). 


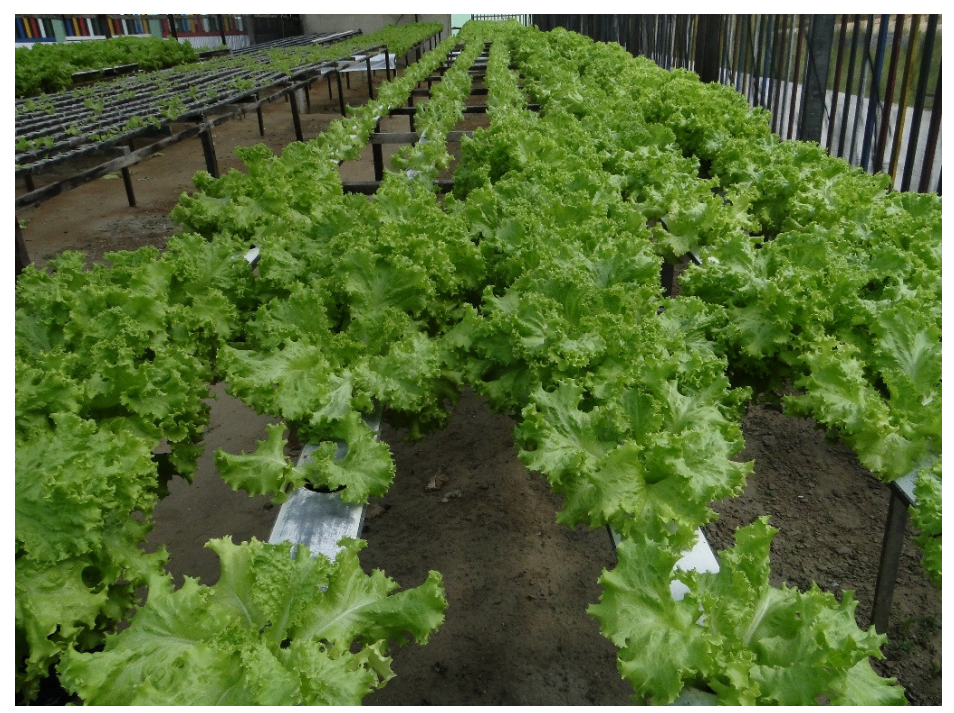

Figura 4: Cultivo hidropônico de alface.

Fonte: Revista Plantar (2010).

Diante desse cenário, e considerando o crescimento exponencial dos parques eólicos no nordeste brasileiro surge como uma alternativa a manutenção do desenvolvimento da agricultura da região o fomento pelas empresas que exploram tal tipo de energia, a compensação ambiental para atenuar os impactos da degradação do solo. Logo, para atender tal premissa entende-se que o ciclo da Figura 5 poderia ser padronizado pelos órgãos fiscalizadores para impor tal prática como uma medida compensatória aos impactos sociais, paisagísticos e econômicos causados pela implantação desses projetos. Esse conceito deriva-se do entendimento do jurista Rodrigues (2007) onde, todavia, não se deve perder de vista que os impactos ecológicos não mitigáveis - tais como a supressão de uma área de preservação, a redução de ecossistemas e perda de biodiversidade são danos que jamais poderão ser recompostos de forma a colocar o meio ambiente no mesmo estado que se encontrava antes de ocorrido o dano. Estamos, pois, no campo da reparação de bens jurídicos imateriais, essenciais ao abrigo e à proteção de todas as formas de vida, de maneira que é impossível encontrar alguma forma de compensação - pecuniária ou in natura - que corresponda, com exatidão, ao valor do bem impactado. Tornando-se tal conceito de reposição subjetivo. 

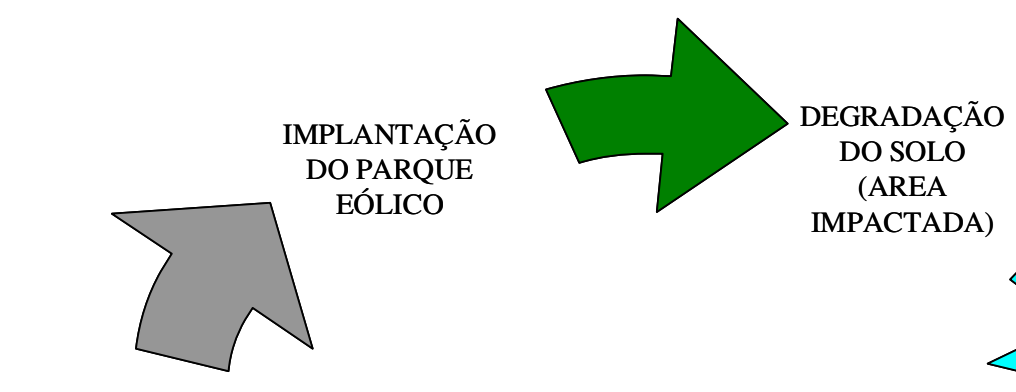

IMPACTADA)

$$
\begin{aligned}
& \text { MANUTENÇÃO } \\
& \text { DAS LICENÇAS } \\
& \text { DE OPERAÇÃO }
\end{aligned}
$$

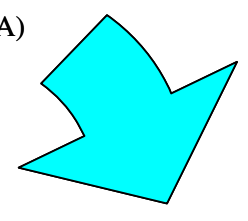

IMPACTOS

SÓCIO-

ECONOMICOS

ENA

AGRICULTURA

LOCAL
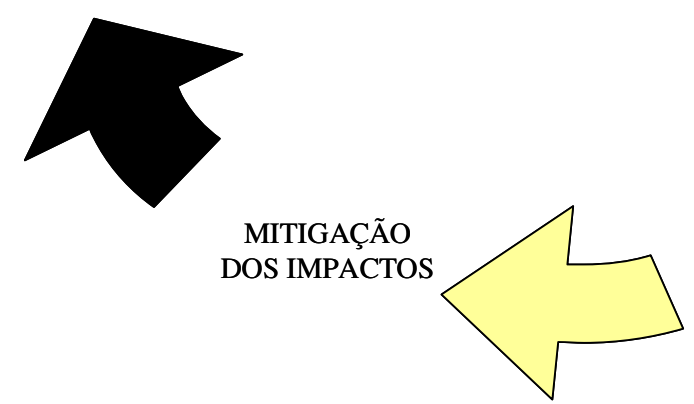

COMPENSAÇÃ

O AMBIENTAL

COM A

HIDROPONIA

Figura 5: Ciclo de compensação ambiental para atenuar danos de áreas degradadas na instalação de parques eólicos. Fonte: Autores.

Porém, para que haja uma definição segura dos danos que uma medida compensatória como essa traria, sobretudo, em áreas de escassez de água como o nordeste brasileiro faz-se necessário uma completa avaliação ambiental. Essa ferramenta é entendida como um instrumento de política ambiental formado por um conjunto de procedimentos capaz de assegurar, desde o início do processo, que se faça um exame sistemático dos impactos ambientais de uma ação proposta (projeto, programa, plano ou política) e de suas alternativas. E que os resultados sejam apresentados de forma adequada ao público e aos responsáveis pela tomada de decisão, e por eles devidamente considerados.

Sendo assim, o objetivo desse trabalho consiste em levantar uma matriz de impactos ao meio ambiente associados pela atividade de hidroponia, como uma alternativa ao uso do solo em áreas degradadas pela implantação de parques eólicos em áreas de escassez de água no nordeste brasileiro. 
Rev. Elet. em Gestão, Educação e Tecnologia Ambiental (e-ISSN: 2236-1170)

\section{METODOLOGIA}

O estudo constitui-se de uma pesquisa aplicada, pois objetiva levar conhecimentos para extensão da hidroponia, cujas oportunidades foram levantadas e avaliadas em estudo de viabilidade técnica e ambiental como alternativa e compensação ambiental para implantação de parques eólicos. Do ponto de vista dos objetivos, trata-se de um estudo exploratório-descritivo, o qual visa descrever a problemática em discussão, buscando caracterizar o objeto de estudo.

A hipótese pauta-se na possibilidade de haver viabilidade técnica e ambiental para considerar a hidroponia como uma alternativa ao uso e ocupação de solo em áreas degradadas pela implantação de parques eólicos, no que concerne à utilização práticas sustentáveis, para atingir um uso racional e eficiente destes recursos.

Do ponto de vista dos procedimentos técnicos, o estudo caracteriza-se como uma pesquisa-Ação, ou seja, quando concebida e realizada em estreita associação com uma ação ou com a resolução de um problema coletivo. Os pesquisadores e participantes representativos da situação ou do problema estão envolvidos de modo cooperativo ou participativo (Silva; Menezes, 2001), e, também, como estudo de caso devido à utilização de dados de campo, sendo as práticas aferidas na implantação em parques eólicos no nordeste brasileiro.

A estrutura da pesquisa consiste em:

- Formulação do problema, englobando a justificativa do estudo, a determinação dos objetivos, a contextualização da problemática e definição da metodologia;

- Realização do levantamento teórico, que orienta a caracterização do objeto de estudo, as definições e conceitos a serem utilizados em análise e correntes de pensamentos que norteiam a hipótese da pesquisa e do conceito de hidroponia;

- Levantamento inicial de dados em campo, por meio de incursões investigativas em parques eólicos.

Os dados coletados em campos foram organizados, de acordo com a necessidade da utilização em pesquisa, e utilizados para elaboração do levantamento das principais ações de oportunidades. E compõe o banco de resposta dos principais indicadores validados.

Após a determinação dos impactos ambientais, foi possível a elaboração de uma matriz de análise de impactos ambientais. O processo de análise foi elaborado, levando-se em conta as alterações causadas ao meio ambiente durante a fase de operação do empreendimento. Essas alterações foram caracterizadas com base nos indicadores ambientais e seus critérios de avaliação, em termos do grau em que alteram a composição dos recursos ambientais. Os indicadores ambientais são: estrutura do solo; propriedades físico-químicas do solo; qualidade das águas superficiais; qualidade das águas subterrâneas; qualidade do ar e qualidade da água do sistema de drenagem pluvial (Rauber et al, 2004). Os critérios de avaliação, utilizados na Matriz de Análise dos Impactos Ambientais, foram:

a) Natureza: indica quando o impacto tem efeitos benéficos/ positivos (POS) ou adversonegativos (NEG) sobre o meio ambiente. 
Rev. Elet. em Gestão, Educação e Tecnologia Ambiental (e-ISSN: 2236-1170)

b) Forma: refere-se ao modo como se manifesta o impacto, ou seja, direto (DIR), decorrente de uma ação do empreendimento, ou indireto (IND), decorrente de outro, ou outros impactos gerados direta ou indiretamente.

c) Duração: é o tempo de impacto, classifica-se em permanente (PER), ou seja, aqueles cujos efeitos manifestam-se indefinidamente e de modo temporário (TEM), aqueles que ocorrem durante um período de tempo determinado e depois cessam.

d) Temporalidade: diferencia os impactos, segundo os que se manifestam imediatamente após a ação impactante (IME), a curto prazo (CP) e aqueles cujos efeitos só se fazem sentir após um período de tempo em relação a sua causa (LP).

e) Reversibilidade: classifica os impactos, segundo aqueles que, depois de manifestados seus efeitos, são irreversíveis (IRR) ou reversíveis (REV). Permite identificar que impactos poderão ser integralmente evitados ou poderão apenas ser mitigados ou compensados.

f) Abrangência: indica os impactos cujos efeitos se fazem sentir no local (LOC) ou que podem afetar áreas geográficas mais abrangentes (REG). Considera-se como efeito local o que se restringe a área de influência direta, a qual se restringe à pluma de contaminação e o regional é aquele que afeta as Áreas de Influência Indireta.

g) Magnitude: refere-se ao grau de incidência de um impacto sobre o fator ambiental, em relação ao universo desse fator ambiental. Ela pode ser grande (GRA), média (MED) ou pequena (PEQ), segundo a intensidade de transformação da situação preexistente do fator ambiental impactado. A magnitude de um impacto é, portanto, tratada, exclusivamente, em relação ao fator ambiental em questão, independentemente da sua importância, por afetar outros fatores ambientais.

h) Importância: refere-se ao grau de interferência do impacto ambiental sobre diferentes fatores ambientais. Pode ser grande (GRA), média (MED) ou pequena (PEQ), na medida em que tenha maior ou menor influência sobre o conjunto da qualidade ambiental local.

\section{RESULTADOS E DISCUSSÕES}

A Tabela 1 apresenta a matriz de impactos ambientais construídas a partir dos dados da pesquisa. Dentre os impactos ambientais avaliadas como negativos (Neg) na matriz (vida selvagem, vegetação, paisagem, solo, sociais e culturais), deve-se observar que a vegetação e o solo, uma vez comprometidos impedem a continuidade normal da produção e a conseqüente interferência na ocupação e renda das pessoas envolvidas. No que diz respeito a legislação, não existe fiscalização da qualidade do solo nem da água utilizada na hidroponia, mas com certeza se usa mais água do que a cultura precisa. 
Rev. Elet. em Gestão, Educação e Tecnologia Ambiental (e-ISSN: 2236-1170)

Tabela 1. Avaliação dos impactos ambientais de uma planta de hidroponia implantada em área de escassez de água no nordeste brasileiro.

\begin{tabular}{|c|c|c|c|c|c|c|c|c|}
\hline \multirow[b]{2}{*}{ Indicadores } & \multicolumn{8}{|c|}{ CRITÉRIOS DE AVALIAÇÃO } \\
\hline & 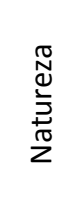 & $\begin{array}{l}\stackrel{0}{\xi} \\
\text { 한 }\end{array}$ & 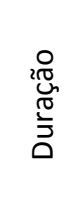 & 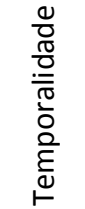 & 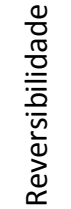 & 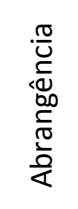 & 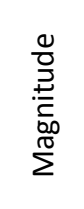 & 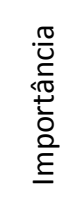 \\
\hline Estrutura do solo & POS & DIR & PER & IME & REV & LOC & PEQ & PEQ \\
\hline $\begin{array}{l}\text { Propriedades físico- } \\
\text { químicas do solo }\end{array}$ & POS & IND & TEM & $\mathrm{CP}$ & REV & LOC & PEQ & PEQ \\
\hline Vida selvagem & NEG & DIR & TEM & IME & REV & REG & MED & MED \\
\hline Paisagem & NEG & DIR & PER & IME & REV & LOC & PEQ & PEQ \\
\hline Sociais & POS & DIR & PER & $\mathrm{LP}$ & IRR & LOC & MED & MED \\
\hline Culturais & NEG & IND & PER & $\mathrm{LP}$ & IRR & LOC & MED & MED \\
\hline Água Subterrânea & NEG & IND & PER & $\mathrm{LP}$ & REV & LOC & MED & MED \\
\hline $\begin{array}{c}\text { Disponibilidade } \\
\text { Hídrica }\end{array}$ & NEG & DIR & PER & $\mathrm{CP}$ & REV & LOC & MED & MED \\
\hline Impacto no ar & POS & DIR & PER & IME & REV & LOC & PEQ & PEQ \\
\hline Economia & POS & DIR & PER & $\mathrm{CP}$ & REV & REG & MED & MED \\
\hline Ed. Ambiental & POS & DIR & PER & $\mathrm{CP}$ & IRR & REG & MED & MED \\
\hline
\end{tabular}

Dentre as medidas mitigadoras dos impactos ambientais a serem desenvolvidos e implantados na hidroponia, é de grande relevância a elaboração de um plano de gerenciamento de riscos, o qual envolve hipótese acidental, medidas preventivas, treinamento dos operários, inspeção e manutenção de equipamentos e plano de contenção para vazamentos.

No plano de contenção para vazamentos, haverá procedimentos e medidas para minimizar impactos de vazamentos de produtos. Os combustíveis e óleos lubrificantes devem ser armazenados em local apropriado, podendo ser colocadas almofadas ou esteiras absorventes, no solo, sob os tanques.

Os impactos ambientais que causam degradação ao meio ambiente na área de influência: contaminação do solo, contaminação da água superficial e subterrânea, poluição do ar, adensamento e compactação do solo. No que se refere a esses impactos, propõe-se: plano de contingência, programas de monitoramento. Para os impactos irreversíveis, sugere-se a implantação de medidas compensatórias. Além dos programas de monitoramento e das medidas compensatórias, recomenda-se programa de gestão ambiental, o qual envolve a implantação do Sistema de Gestão Ambiental da usina, nos moldes da série ISO 14001, bem como, o desenvolvimento de análises quantitativas dos impactos. 
Rev. Elet. em Gestão, Educação e Tecnologia Ambiental (e-ISSN: 2236-1170)

\section{CONSIDERAÇÕES FINAIS}

Com esses processos da aplicação da técnica de hidroponia, com a adição de água com nutrientes em pouca concentração, objetivasse conseguir: boa produtividade de massa verde (forragem), baixo custo, maior valor nutricional (energia e proteína, em relação ao convencional), menos intervalo de tempo de colheita e principalmente comprovar uma verdade alternativa de uso útil do solo para áreas degradadas, onde não mais é possível sua utilização direta.

Um dos fatores limitantes para o uso de sistemas hidropônicos é o custo inicial elevado, com a compra dos equipamentos, para isso, recomenda-se criação de grupos de cooperativas ou associações de agricultores para viabilizar este processo no segmento financeiro, bem como as devidas assistências técnicas, pelos grupos atuais de assistência como a EMATER e EMPARN do país. A assistência técnica é indispensável, se tratando de uma técnica como está, onde se faz necessário a manipulação de diversas substâncias, não devendo ser manipulado em concentrações erradas. Essa medida está associada as questões sociais, econômicas e educacionais envolvidas nos impactos avaliados pela matriz.

As áreas degradadas podem ter agora novas finalidades de uso, que mesmo não diretos, podem trazer melhorias para as populações que nessas regiões se fizerem presentes e dependerem do uso direto do solo para seus sustentos. Visto que a matriz não apresentou impactos em níveis de alto grau de significância.

O modelo de compensação é positivo, pois os pontos de aumento de produção e diminuição de tempo no ciclo podem ser superados pela hidroponia. Sendo também observado que no que diz respeito ao uso e ocupação do solo em áreas degradadas pelos mais diversos fatores químico, físico e biológico, tem-se um melhor aproveitamento cada espaço e dando condições para a produção de hortaliças e forragem para o sustento de famílias que sobrevivem da agricultura e pecuária. Além disso, fomenta-se o uso racional da água e a não utilização de produtos tóxicos e máquinas que compactem o solo, ou seja, foram dispensados fatores que prejudicassem mais ainda o meio ambiente.

\section{REFERENCIAS BIBLIOGRÁFICAS}

CASTRO, R. M. G. INTRODUÇÃO À ENERGIA EÓlICA. Disponível em: http://energia.ist.utl.pt/ruicastro. Acesso em: 20/10/2012. 2011.

DIAS, N. da S.; LIRA, R. B.; BRITO, R. F.; SOUZA Neto, O. N.; FERREIRA Neto, M.; OLIVEIRA, A. M. Produção de melão rendilhado em sistema hidropônico com rejeito da dessalinização de água em solução nutritiva. Revista Brasileira de Engenharia Agrícola e Ambiental, v.14, p.755-761, 2010.

FRANÇOIS, L. E. Salinity effects on four sunflower hybrids. Agronomy Journal, v.88, p.215-219, 1996.

JOHNSON, D. L., et al. Meanings of environmental terms. Journal of Environmental Quality, n. 26, p.584. 1997. 
REGESTIFSM VASCONCELOS \& JERÔNIMO, v(8), no 8, p. 1794-1804, SET-DEZ, 2012.
Rev. Elet. em Gestão, Educação e Tecnologia Ambiental (e-ISSN: 2236-1170)

MACIEL, M. P. R. Produção de girassol ornamental com uso de águas salobras em sistema hidropônico NFT. Bras. Eng. Agrícola Ambiental, v.16, n.2, p.165-172, 2012.

MARTINS, S. V. Recuperação de Áreas Degradadas: ações em áreas de preservação permanente, voçorocas, taludes rodoviários e mineração. Aprenda Fácil. Viçosa, MG, 2009.

PLANTAR. Hidroponia. Disponível em: http://www.revistaplantar.com.br/alface-e-o-cultivohidroponico/. Acesso em 05/05/2012.

RAUBER, A. C. C. et al. Diagnóstico de impactos ambientais causado por usina de asfalto. Disc. Scientia. Série: Ciências Naturais e Tecnológicas, S. Maria, v. 5, n. 1, p. 97-106, 2004.

REBOUÇAS, A. C. Águas subterrâneas. In: Rebouças, A. C.; Braga, B.; Tundisi, J. G. (ed.). Águas doces no Brasil: capital ecológico, uso e conservação. São Paulo: Escrituras, 1999. cap. 4, p. 117151.

RODRIGUES, M. A. Aspectos jurídicos da compensação ambiental do art. 36, $\$ 1$ 으 dei Brasileira das Unidades de Conservação (Lei no. 9.985/2000). 2 ed. rio de Janeiro: Forense Universitária, 2004.

SÁNCHEZ, L. H. Avaliação de Impacto Ambiental: conceito e métodos. Oficina de Textos, São Paulo, 2008. p 26.

SANTOS Júnior, J. A.; GHEYI, H. R.; GUEDES Filho, D. H.; DIAS, N. da S.; SOARES, F. A. L. Cultivo de girassol em sistema hidropônico sob diferentes níveis de salinidade. Revista Ciência Agronômica, v.42, p.842-849, 2011.

SILVA, E. L. MENEZES, E. M. Metodologia da pesquisa e elaboração de dissertação. 4ed. Florianópolis - SC. 2005. 138p.

SOARES, I. Alface: cultivo hidropônico. Fortaleza: Ed.UFC, 2002 (Série Didática, 7).

STAFF, H. Hidroponia; Cuiabá: SEBRAE\MT. 1997. 86p; Coleção Agroindústria; v. 11.

TRAVASSOS, K. D.; SOARES, F. A. L.; GHEYI, H. R.; SILVA, D. R. S.; NASCIMENTO, A. K. S.; DIAS, N. da S. Produção de aquênio do girassol irrigado com água salobra. Revista Brasileira de Engenharia Agrícola e Ambiental, v.15, p.371-376, 2011. 